\title{
El control difuso de la constitucionalidad de las normas jurídicas
}

Karla Pérez Unzueta

Abogada por la Universidad Nacional Mayor de San Marcos. Maestría en Derecho por la Universidad Nacional Federico Villarreal y la Universidad Alas Peruanas. Relatora de la 1ra. Sala Civil de Lima Norte.
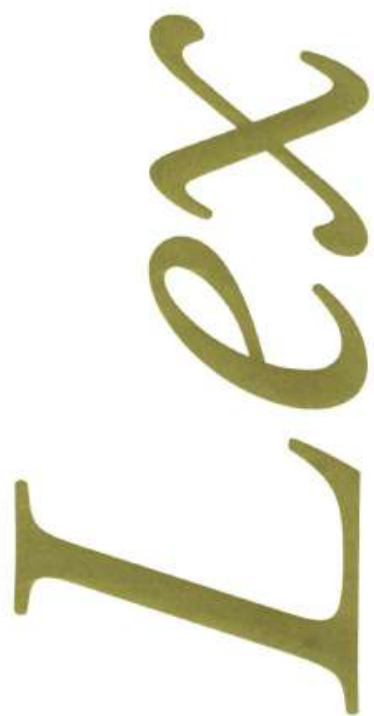


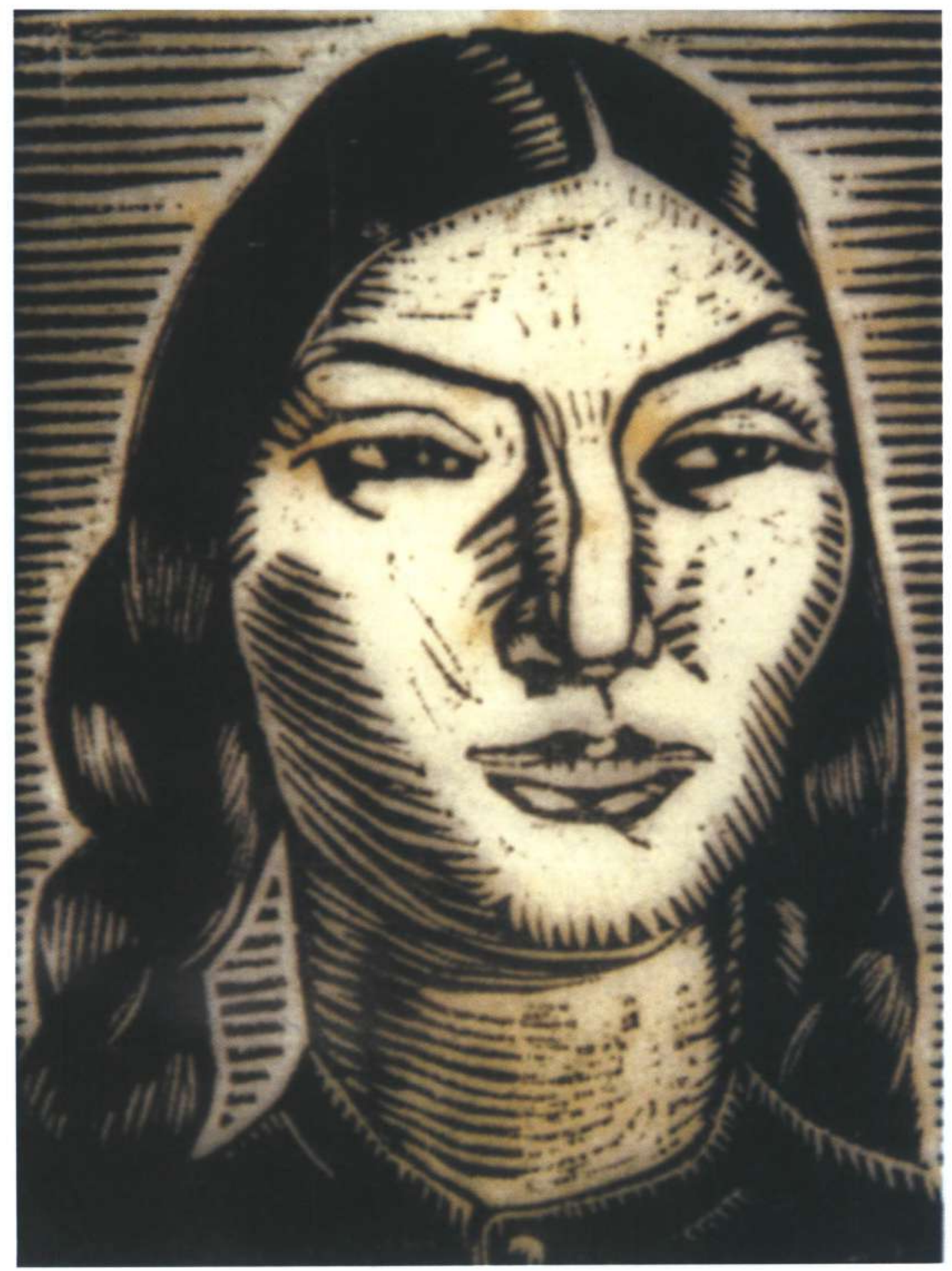

Cholita 
I presente trabajo tiene por finalidad efectuar un estudio del Control Difuso de la Constitucionalidad de las Normas Jurídicas, considerado en el artículo $138^{\circ}$ de la Constitución de 1993, como un mecanismo de defensa de la supremacía normativa de la Constitución y reservado para aquellos órganos constitucionales que, como el Poder Judicial, ejercen funciones jurisdiccionales. Sin embargo, se sabe que hay en nuestro medio otros organismos constitucionales que siendo autónomos resuelven en última instancia, es el caso del Jurado Nacional de Elecciones o el propio Tribunal Constitucional. Asimismo, existen organismos administrativos que sin ser jurisdiccionales, como el Tribunal Fiscal, resuelven controversias en las materias que les corresponde. Cabe entonces preguntar: ¿podrían algunos de estos organismos, al igual que los jueces, inaplicar una norma por considerarla inconstitucional?

La Constitución de 1993, prevé en el Perú el control concentrado de constitucionalidad de las leyes, atribuyéndolo al Tribunal Constitucional como máximo intérprete de la Constitución. Empero, también lo que por oposición se conoce como sistema de control difuso aquél en que cualquier tribunal puede declarar la inaplicabilidad de un precepto legal o de inferior jerarquía, que sea contrario a la Constitución, en el caso particular del cual conoce (artículo 138). En consecuencia, respondiendo a la pregunta si pueden otros organismos, diferentes al Poder Judicial, inaplicar normas consideradas inconstitucionales, la respuesta la ha ido dando el Tribunal Constitucional en sentencias de procesos de amparo, y que a nuestro modesto entender han dado un paso importante en lo que significa la aplicación del Control Difuso en sede administrativa, aun cuando sólo puede ser aplicada por ciertos órganos constitucionales que ejercen funciones jurisdiccionales en las materias que les corresponde y no para los órganos de naturaleza o competencias eminentemente administrativas.

\section{Constitucionalidad}

La constitucionalidad es una categoría jurídico-política que implica la existencia de una Constitución en un determinado Estado y que dicha Constitución esté plenamente vigente, que tenga 
vigor, se la respete y aplique adecuadamente. Los fundamentos de la Constitucionalidad son la supremacía constitucional, la jerarquía de las normas jurídicas y la inviolabilidad constitucional' .

\section{Control Constitucional}

Debe entenderse como control constitucional, al conjunto de medidas y procedimientos, ya sea de carácter político o parlamentario, jurisdiccional y social, que está destinado a hacer posible se respete y mantenga un estado de constitucionalidad, como base para el orden jurídico, la estabilidad política y el equilibrio social. Dentro de las formas de control constitucional, precisamente, existe el control constitucional jurisdiccional, a cargo de los Tribunales o Cortes Constitucionales y del Poder Judicial. Y dentro de este tipo de control constitucional, existen tres sistemas: concentrado o austriaco, difuso o norteamericano, y político o francés

\section{- Conceptos y características del Control Concentrado}

El control concentrado de constitucionalidad de la ley es el que se reserva a un solo órgano, sea éste el Tribunal Supremo de Justicia, sea una Sala Constitucional del mismo, sea este un Tribunal Constitucional autónomo, con exclusión de los demás tribunales.

Cuando la sentencia que dicta el órgano de control invalida o deroga la norma inconstitucional, se habla de control abstracto, que tiene efectos generales o «erga omnes».

- Conceptos y características del Control Difuso

El sistema de Control Difuso es aquél en el que cualquier tribunal puede declarar la inaplicabilidad de un precepto legal o de inferior jerarquía, que sea contrario a la Constitución, en el caso particular del cual conoce. Cuando la misma sentencia sólo deja sin aplicación el precepto legal en el caso de que se trate, se habla de control concreto de constitucionalidad, que tiene efecto particular o "inter partes", quedando vigente la ley inaplicada ${ }^{2}$.

De tal experiencia y de su teoría, se han extraído las siguientes características:

Víctor Julio Ortecho Villena, Control Difuso e Interpretación Constitucional. Disponible en http://hechosdelajusticia.org/ quinta/38.rtf

2 Ríos A., Lautaro. El Control Difuso de Constitucionalidad de la Ley en la República de Chile. . Ius et Praxis. [online]. 2002, vol.8, no.1 [citado 15 Octubre 2006], p.389-418. Disponible en la World Wide Web: http://www.scielo.cl/ scielo.php?script=sci_arttext\&pid=S0718-00122002000100021\&lng=es\&nrm=iso >. ISSN 0718-0012. 
a) Se plantea como excepción, en vía de incidente y en un caso particular o concreto.

b) El juez al resolver se pronuncia sobre la inaplicabilidad de la norma inconstitucional.

c) Los efectos de la sentencia se aplican únicamente a las partes que concurren al proceso, es decir es de efectos interpartes.

\section{-Antecedentes del Control de la Constitucionalidad}

El control de la Constitucionalidad en general, tiene su más remoto antecedente en Inglaterra. Fue sir Edward Coke, quien en 1610, declaró, en Doctor Bohan's Case, el principio de «supremacía del Common law» sobre el absolutismo del rey, e, incluso sobre la soberanía del parlamento ${ }^{3}$. Sin embargo, estas ideas no tuvieron eco en el arraigado parlamentarismo que caracteriza al sistema inglés. No obstante, fueron aprehendidas por las colonias americanas con características propias, específicamente en el caso Marbury vs. Madison, resuelta por el juez Marshall en 1803, como lo veremos más adelante.

- Métodos del Control de la Constitucionalidad de las Leyes

El Derecho Procesal Constitucional contemporáneo reconoce básicamente tres métodos o «modelos» del control de la constitucionalidad de las leyes:

a) El llamado control difuso o americano, o judicial review, denominado también «revisión judicial de la constitucionalidad de las leyes». Todas estas acepciones son sinónimas y, como ya lo expresamos desde las páginas del diario El Comercio (13.09.96), nace en los Estados Unidos, cuando en 1803 la Suprema Corte Federal sentencia una Acción de Cumplimiento (Writ Of Mandamus) en el leading case Marbury vs. Madison, y en donde se "descubre", pues la Constitución norteamericana no lo contemplaba ni lo contempla, expresamente que los jueces del Poder Judicial pueden declarar, en un caso o controversia concreta sometida a su juzgamiento, si una Ley del Congreso de necesaria aplicación en dicho caso, es o no constitucional; de manera que al determinar que no lo es efectúa una «derogación de la ley para el caso concreto materia de su juzgamiento»; esto es, determina su inaplicabilidad por colisión constitucional.

Esto significa que tal facultad nace sólo dentro del Poder Judicial, es una consecuencia del accionar del derecho y la realidad, aplicable sólo en una controversia específica, real y concreta, donde los márgenes de la declaración judicial de inconstitucionalidad no va más allá de los linderos del expediente, no versa sobre cuestiones políticas, no es abstracta y a ello sólo se debe

3 García Pelayo, Manuel. 1961, «Derecho Constitucional Comparado». Madrid. 6ta. Edición. Castilla. Pág. 262 y SS. 
llegar luego de presumirse la constitucionalidad de la ley y agotadas todas las posibilidades interpretativas en favor de la ley dubitada.

b) El segundo modelo o sistema de control de la constitucionalidad es del presente siglo, nace bajo la impronta de Hans Kelsen, célebre jurista vienés, y recusa el control judicial de la constitucionalidad de las leyes, optando por darle esa responsabilidad a un órgano autónomo e independiente, que se gesta para contrarrestar el enorme poder del Congreso y la posibilidad cierta (comprobada en más de 100 años de constitucionalismo) de sus excesos en contra de la Constitución. A este modelo se le llama el "concentrado", se caracteriza por dejar en manos de un tribunal ad hoc la función de control; no toma en cuenta el caso que dio motivo a su cuestionamiento y analiza la norma de manera aislada ${ }^{4}$. El control se concentra en un sólo órgano, el Tribunal Constitucional, a diferencia del anterior en que se halla «difundido» o "difuminado" en todo un sistema judicial. Es decir, la sola presencia de un Tribunal Constitucional determina la opción del modelo "concentrado" de justicia constitucional; con una actuación que es abstracta y tiene capacidad para derogar toda una ley -no sólo inaplicarla- cuando determine su colisión constitucional.

c) Al lado de los otros dos, se reconoce un subsistema, el francés, creado en la Constitución de la V República de 1958, a impulso de Charles de Gaulle, que determina el control preventivo de las leyes, en su fase de formación con la revisión de la constitucionalidad de los proyectos de ley por parte del Conseil Constitutionnel, aprobándose sólo leyes previamente «vacunadas» de constitucionalidad.

Será en América Latina donde, muy peculiarmente, a partir de la segunda mitad del siglo XX se va a dar una fusión de los dos sistemas puros de control -el difuso y el concentrado-. El modelo difuso fue insertado en las constituciones de muchos países americanos entre el siglo XIX y primera mitad del siglo XX, por ejemplo; Colombia en 1910, Venezuela en 1858; México en 1857; Perú en 1856.

Sin embargo, el éxito del constitucionalismo europeo de la posguerra hizo que los tribunales constitucionales se expandieran también en nuestro continente ${ }^{5}$, de tal forma que existen sistemas que son puramente concentrados: Paraguay, Uruguay, Panamá; y otros países donde se juntan ambos modelos: Colombia, El Salvador, Venezuela, Guatemala, Brasil, México, Perú y Bolivia.

4 Blume Fortini, Ernesto. El Tribunal Constitucional Como Supremo Intérprete de la Constitución. Derecho PUC, núm. 50. Diciembre de 1996. pág. 132.

5 Landa, César. Tribunal Constitucional y Estado de Derecho. Lima, PUCP, 1999. pág. 56 
El Código Civil Peruano de 1936, reconoció en su artículo XXII, el modelo de la revisión judicial de las leyes, siendo ratificado por la Ley Orgánica del Poder Judicial de 1963 (artículo 8), la Constitución de 1979 (artículo 236), la actual LOPJ (artículo 14) y el artículo 138 de la Carta Política de 1993 en vigencia. Pero, desde 1979 coexiste con el sistema concentrado creado con el ex Tribunal de Garantías Constitucionales, hoy actualizado como Tribunal Constitucional. Es decir, nuestro sistema de control constitucional es mixto o dual -como lo llama García Belaúnde -y así debe ser reconocido cuando sea objeto de cualquier análisis ${ }^{6}$.

\section{Criterios señalados por el Tribunal Constitucional}

A continuación presentamos una serie de criterios señalados por el Tribunal Constitucional para el adecuado ejercicio de este mecanismo de defensa de la supremacía normativa de la Constitución.

- El Control Difuso como potestad exclusiva de los Órganos Jurisdiccionales del Estado

El Tribunal Constitucional ha señalado que «(...) la facultad de declarar inaplicables normas jurídicas, conforme a lo que establece el artículo $138^{\circ}$ de nuestra Constitución Política, sólo se encuentra reservada para aquellos órganos constitucionales que, como el Poder Judicial, el Jurado Nacional de Elecciones o el propio Tribunal Constitucional, ejercen funciones jurisdiccionales en las materias que les corresponden y no para los órganos de naturaleza o competencias eminentemente administrativas». (Sentencia del expediente 007-2001-AI/TC, publicada el 1 de febrero de 2003, fundamento 3)

Así por ejemplo, el Tribunal Constitucional ha señalado que el Tribunal Fiscal no sería un órgano competente para inaplicar una norma tributaria que sea inconstitucional. En ese sentido ha precisado en reiterada jurisprudencia que el Tribunal Fiscal (...) en la medida que (...) no posee el rango de órgano jurisdiccional, no es competente para declarar la inaplicabilidad de leyes o normas con rango de ley, pues tal actuación contravendría la Constitución». (Sentencia del Expediente 0499-2002-AA/TC, publicada el 18 de junio de 2003, fundamento 1).

- Los criterios para decidir la inaplicación de una Norma

De acuerdo al Tribunal Constitucional, el ejercicio del control difuso es un acto complejo, puesto que conlleva la inaplicación al caso concreto de una norma que en un inicio se presume constitucional. En reiterada jurisprudencia, ha establecido los criterios que deben ser tomados en cuenta por los

“Aníbal Quiroga León, El difuso "control difuso». Diario El Comercio. Viernes 24 de enero de 1997. 
jueces para inaplicar una norma en el marco de un proceso de amparo. Estos criterios son:

a. En el caso concreto que da lugar a un proceso de amparo, el acto impugnado debe constituir una aplicación de la norma considerada inconstitucional (artículo 3 de la Ley 23506).

b. La norma a inaplicarse debe tener una relación directa, principal e indisoluble con la resolución del caso, es decir, ella debe ser relevante para la resolución de la controversia.

c. La norma a inaplicarse debe resultar evidentemente incompatible con la Constitución, aun luego de haberse acudido a interpretarla de conformidad con ella, en virtud del principio recogido en la Segunda Disposición General de la Ley Orgánica del Tribunal Constitucional.

\section{Casos en los que el Tribunal Constitucional ha empleado estos criterios}

Mencionamos a continuación tres situaciones en las que el Tribunal Constitucional ha empleado estos criterios para declarar inaplicable una norma en un proceso de amparo:

Caso de los trabajadores de la empresa Telefónica del Perú (Sentencia del Expediente 1124-2001, publicada el 11 de septiembre del 2002)

Un grupo de trabajadores de la empresa Telefónica del Perú presentó una demanda de amparo contra la decisión de esta empresa de separarlos de su puesto de trabajo, medida que fue adoptada con base al artículo 34 de la Ley de Productividad y Competitividad Laboral (Decreto Legislativo 728, Texto Único Ordenado: Decreto Supremo 003-97-TR). El texto de la norma mencionada dispone: «Si el despido es arbitrario por no haberse expresado causa o no poderse demostrar esta en juicio, el trabajador tiene derecho al pago de la indemnización establecida en el artículo 38, como única reparación por el daño sufrido. Podrá demandar simultáneamente el pago de cualquier otro derecho o beneficio social pendiente.»

En este caso el Tribunal analizó la mencionada disposición y llegó a la conclusión de que la misma resultaba inconstitucional, por contravenir el derecho a no ser despedido sino por causa justa. A efectos de inaplicarla al caso concreto, tomó en consideración los criterios mencionados y realizó el siguiente razonamiento:

a) El acto de despido realizado por el empleador se sustenta en la norma contenida en el citado artículo $34^{\circ}$ (segundo párrafo);

b) La constitucionalidad o no de esta norma es relevante para la resolución del proceso debi- 
do a que los despidos tienen como fundamento el artículo $34^{\circ}$ (segundo párrafo); $\mathrm{y}$, finalmente;

c) El hecho de que no es posible interpretar el citado artículo de conformidad con la Constitución, pues resulta evidentemente inconstitucional (...).

En consecuencia, el Tribunal declaró fundada la demanda de amparo e inaplicable al caso concreto el citado artículo 34, segundo párrafo. Para esta instancia, «al haberse efectuado los despidos de acuerdo con un dispositivo inconstitucional como el citado artículo $34^{\circ}$, segundo párrafo, dichos actos resultan nulos.»

Esta sentencia del Tribunal originó bastante polémica, por cuanto no quedaba claro si el Tribunal había considerado inconstitucional todo el segundo párrafo del artículo $34^{\circ}$ o solamente una parte de él. En su aclaración de la sentencia, el Tribunal señaló que la inconstitucionalidad fue respecto al artículo 34, ab initio. En ese sentido señaló: «La inaplicación del segundo párrafo del artículo $34^{\circ}$ del Decreto Legislativo $\mathrm{N}^{\circ} 728$, en concreto, está referida a la inconstitucional atribución conferida por el legislador ordinario para practicar despidos individuales sin expresión de causa».

\section{Casos de jueces y fiscales destituidos a través de Decretos Leyes}

Varios ex integrantes del Poder Judicial y del Ministerio Público presentaron demandas de amparo contra decretos leyes emitidos durante el gobierno del ex presidente Alberto Fujimori, a través de los que se dispuso su destitución como jueces y fiscales. Tales normas, asimismo, impedían acudir al proceso de amparo para impugnar esta medida.

En esos casos, el Tribunal consideró que la prohibición para acudir al proceso de amparo resultaba inconstitucional. $\mathrm{Al}$ inaplicar los decretos leyes al caso concreto, ha señalado:

a) El mandato dirigido a rechazar la interposición de acciones de amparo contra los efectos derivados de la aplicación de los decretos leyes es contrario no sólo a la Constitución de 1979, sino también a la vigente, así como a la Convención Americana de Derechos Humanos;

b) La constitucionalidad o no de esta norma es relevante para la resolución del proceso debido, dado que constituía un impedimento para acceder a los tribunales internos en busca de la protección de sus derechos fundamentales; $y$,

c) El hecho de que no es posible interpretar las normas antes citadas, de acuerdo con la Constitución, por ser evidentemente inconstitucionales, conforme se ha anotado. 
En consecuencia, el Tribunal ha declarado fundadas estas demandas de amparo e inaplicables los decretos leyes cuestionados, según cada caso. Algunas de las sentencias en donde se ha aplicado este criterio son las siguientes:

1) Sentencia del expediente 1109-2002-AA/TC (caso Isaac Gamero Valdivia), publicada el 18 de noviembre del 2002. En este caso, el Tribunal declaró inaplicable los Decretos Leyes 25423 y 25454, y ordenó la reincorporación del demandante al cargo de Vocal Titular de la Corte Suprema de Justicia.

2) Sentencia del expediente 1383-2001-AA/TC (caso Luis Alfredo Rabines Quiñónez), publicada el 21 de noviembre de 2002. En este caso, el Tribunal declaró inaplicable el Decreto Ley 25735 y ordenó la reposición del demandante al cargo de Fiscal Superior Titular del Distrito judicial de La Libertad.

3) Sentencia del expediente 605-2002-AA/TC (caso Gloria Villagómez Olivera de Deza), publicada el 13 de marzo del 2003. En este caso el Tribunal declaró inaplicable el Decreto Ley 25735 y 25991, y ordenó la reincorporación de la demandante al cargo de Fiscal Provisional Adjunta Titular en lo Penal del Distrito Judicial de Arequipa.

4) Sentencia del expediente 1687-2002-AA/TC (caso Artemio Bardales Ríos), publicada el 2 de abril del 2003. En este caso, el Tribunal declaró inaplicables los Decretos Leyes 25530, 25735 y 25991, y ordenó la reincorporación del demandante al cargo de Auxiliar de Fiscal Provincial. 2003)

Caso Calcosta S.A. (Sentencia del Expediente 649-2002-AA/TC, publicada el 5 de abril del

La empresa Calcosta S.A. interpuso una demanda de amparo contra la decisión mediante la cual se anuló su ficha registral de propiedad sobre un inmueble, a favor de otra empresa que tenía una ficha más antigua. La decisión en cuestión fue adoptada con fundamento en el artículo 171 del Reglamento General de los Registros Públicos. Al respecto, el Tribunal consideró que el citado artículo 171 de dicho reglamento atentaba contra el derecho a la igualdad. Los argumentos fueron los siguientes: «(...) dicha disposición es incompatible con la Constitución, pues el término de distinción establecido por el referido artículo $171^{\circ}$-cierre de la partida menos antigua y prevalencia de la mayor-, no tiene una causa objetiva y razonable que fundamente la desigualdad, ni tampoco una debida justificación respecto del porqué de la misma, toda vez que se generan consecuencias distintas entre las partes. En efecto, la Oficina Registral, con tal decisión, esto es, la de cerrar sólo una de las partidas -y no afectar la otra-, por el hecho que una sea 
de mayor antigüedad, privilegia a una de las partes con respecto a la otra, pues la que no ha sido objeto de cierre, al disponer de su inmueble y para efectos registrales, podrá lograr su inscripción, lo que no puede hacer la actora, tanto más, cuando entre ellas podría estar dilucidándose, en vía ordinaria, la controversia respecto del mejor derecho de propiedad.»

En ese sentido, el Tribunal declaró inconstitucional el mencionado dispositivo y decidió su inaplicación al caso concreto por las siguientes razones:

a) El acto de cierre de la partida menos antigua realizado por la emplazada se sustenta en la norma contenida en el artículo 171 del Reglamento de Registros Públicos que, como ha quedado dicho, establece un trato desigual e irrazonable.

b) La constitucionalidad o no de esta norma resulta relevante para la resolución del presente proceso, pues el acto concreto de aplicación se produjo por el cierre de partida, teniendo como fundamento el precitado artículo 171; y,

c) No es posible interpretar el citado artículo de conformidad con la Constitución, pues resulta evidentemente inconstitucional y vulneratorio de los derechos de defensa y de igualdad, conforme se ha sostenido en los fundamentos (de la sentencia) ${ }^{7}$

\section{El Control Difuso y el Tribunal Constitucional}

¿Puede el Tribunal Constitucional aplicar el sistema de control concentrado y control difuso, indistintamente?

Dentro de este rubro de ideas conviene determinar en este punto si el Tribunal Constitucional posee, en la acción de control directo de la constitucionalidad de las leyes, la facultad del "control difuso" o de Judicial Review de que trata la segunda parte del Art. $138^{\circ}$ de la Carta Constitucional.

El llamado «Sistema difuso» o de Judicial Review de la constitucionalidad de las leyes basa su esencia y cualidad en dos aspectos fundamentales que le dan la denominación y principales características, una funcional y otra espacial; a saber: la primera, que se halla sistemáticamente ubicado como atributo constitucional «innominado» de toda Constitución escrita.

Red de Información Juridica Jurisprudencia Constitucional, Jurisprudencia sobre el control difuso de la constitucionalidad de las normas juridicas Peri. Disponible en: http: //www.cajpe.org.pe/RIJ/bases/juris-nac/difuso.htm 
En primer lugar, hoy en día, en los países en que se la ha incorporado, ello aparece expresamente y siempre dentro del Capítulo del Poder Judicial (por eso la denominación de "sistema difuso»), esto es, atributo "distribuido" o "difundido" entre todos los órganos del Poder Judicial, en todos los agentes del Poder Judicial en cuanto funcionen u operen como tales. Se dice "difuso" porque no hay ni un órgano específico ni un procedimiento directo para tal, pues se halla difuminado, difundido entre todos los Jueces del Poder Judicial), como un atributo de éste y no susceptible de "transvase" por la vía interpretativa o analógica a otros órganos del Estado.

En segundo lugar, es absolutamente unánime que en su modelo de origen, el sistema solo opera en el escenario de un proceso judicial concreto y real. Esto es, la facultad judicial de oponer su interpretación de una ley del Congreso, dando por resultado la descalificación de la segunda, siempre para el caso concreto y sólo con efectos interpartes y mediante declaración judicial de «inaplicación», sólo será constitucionalmente válida y jurídicamente posible, en los márgenes de un caso concreto donde la ley sea dubitada por ser precisamente aquella con la que el juzgador ordinario debe de decidir ineluctablemente la controversia judicial. Esto es, el único escenario válido en el que el juzgador ordinario abre su facultad constitucional de juzgar la inconstitucionalidad de una ley será su confrontación, en un caso concreto, con los bienes jurídicos tutelados materia de una real controversia judicial, sólo en tanto y en cuanto esa ley entre necesariamente al examen en su aplicación concreta, real y tangible. Así aparece de modo uniforme entre nosotros en los artículos $138^{\circ} 2$ da. Parte, de la Constitución de 1993 en vigencia, y $14^{\circ}$ del vigente TUO de la LOPJ.

Esto quiere decir que la justicia constitucional determinada bajo el esquema o modelo anglosajón de la Judicial Review es, en realidad, una justicia constitucional subsidiaria, residual y fundamentalmente subjetiva. En ese sentido fundamentamos lo siguiente:

Subsidiaria, porque sucede necesariamente a la tarea judicial ordinaria de los Tribunales de Justicia y donde esta facultad es discrecional del juez ordinario de poder hacer, además, de juez constitucional;

Residual, porque la actividad de control constitucional que hace el juez ordinario está «añadida" a su tarea principal, donde el control constitucional indirecto y limitado al "caso concreto", «interpartes", nunca le puede relevar de su función de hacer "reparto" o "distribución de los bienes jurídicos tutelados» -cualquiera sea la naturaleza, dimensión o denominación de éstosmateria de la controversia judicial; y

Subjetiva, porque la determinación de la constitucionalidad o no de una norma legal, que el juez ordinario puede hacer recreando su función judicial con la de «contralor concreto de la 
Constitución" sólo parte -como fuente- de la controversia de derechos subjetivos, de partes subjetivas, de sujetos del proceso judicial ordinario. Esto define a la justicia constitucional americana como una «justicia subjetiva» porque es el derecho de los sujetos, su derecho subjetivo concreto, determinado y determinable -y su actuación en una realidad determinable-, el que servirá de base y sustento del examen de constitucionalidad.

Como se puede apreciar, la justicia constitucional concertada, o ad hoc, bajo el modelo kelseniano, y que corresponde al Tribunal Constitucional es un ejercicio constitucional, mental y metodológico absolutamente opuesto al anterior. Son entonces conceptos antitéticos, hasta opuestos. Y ello surge así desde la no receptividad del sistema americano en la Europa de finales del siglo pasado e inicios de la presente centuria (la doctrina francesa la llegó a denominar la "dictadura de los jueces» aludiendo a su no legitimación directa), y que se hacen sobre la base de metodologías opuestas.

No cabe hacer un juicio valorativo, axiológico, de cualidad de la una sobre la otra, ni viceversa; simplemente cabe enunciar sus diferentes objetivas. Mientras aquella es subjetiva, esta es abstracta puesto que no requiere de contención subjetiva ninguna, ni se hace en sede judicial. Mientras aquélla es para el caso concreto, esa es erga omnes. Mientras aquella está difundida entre todo el sistema judicial, con todas sus variantes, ésta se halla concentrada en un solo órgano expresa y específicamente diseñado en la Constitución. Mientras aquella surge que determina el derecho en conflicto con la realidad, la realidad que enmarca su proceso judicial, ésta proviene de un examen objetivo de subsunción dentro de la simple confrontación de las interpretaciones del referente constitucional y de la interpretación de la norma dubitada.

Tal diferenciación y antagonismo ya había sido puesto de relieve por Mauro Cappelletti y John Clarke Adams cuando afirmaron que: «Esta coexistencia, cuando no incluso conjunción, de modelos dispares, nos enfrenta a la necesidad de abordar una cuestión nada pacífica entre la doctrina: la compatibilidad o incompatibilidad del sistema difuso de control de la constitucionalidad con todos los sistemas jurídicos, esto es, con los sistemas anglosajones o de Common Law y con los de tradición romano-canonista o civil. (...) existe una incompatibilidad fundamental entre el control difuso de la constitucionalidad de las normas y los sistemas de tradición romanista. (...) la experiencia italiana y alemana anterior a la constitucionalización de sus respectivos Tribunales Constitucionales revela la desadaptación del modelo difuso respecto de los países con sistemas jurídicos de derecho civil. Entre los varios argumentos esgrimidos en defensa de (esta) posición (...) (se) advierten (los riesgos) que el método difuso pueda conducir a una grave incertidumbre y confusión cuando un Tribunal decide aplicar una ley y otro la considera inconstitucional. Finalmente en cuanto a este punto, es deber racional reconocer que la doctrina del Tribual Constitucional en la Justicia Constitucional Ad-hoc o concentrada es 
mucho más poderosa, excelsa y directa en la defensa de la Constitución, en tanto que el control constitucional del Poder Judicial es derivado subsidiario y mediatizado al caso concreto. Por eso mayoritariamente la tendencia moderna opta sin ambages por el sistema del tribunal constitucional en el modelo de justicia constitucional concentrado o $A d$-hoc antes que por repetir la fórmula jurisprudencial de la "Judicial Review» basada en el Poder Judicial, no siempre dispuesto o en aptitud de repetir el modelo norteamericano, con sus alcances y limitaciones, y no siempre dotados de la ventaja comparativa que el sistema del stare decisis, o de precedente vinculante como fuente principal de derecho, confiere a la sentencia en el Common Law.

Respondiendo a la pregunta inicial, es preciso indicar que el Tribunal Constitucional no puede, ni debe, ejercer la Judicial Review cuando conoce de una acción de inconstitucionalidad de las leyes, por ser esta abstracta, por pertenecer aquella (la Judicial Review) a la competencia exclusiva y excluyente del Poder Judicial conforme a la segunda parte del Art. 138ㅇ de la Carta Constitucional, inequívoca y sistemáticamente situado dentro del Poder Judicial (lo que la Constitución reserva expresamente para un órgano, veda implícitamente para otro). Sin embargo, lo anterior no opera igual en la competencia del Tribunal Constitucional para conocer de la jurisdicción negativa de la libertad (artículo 202ํㅡㄹ inciso 2 de la Constitución), dado que en dicha facultad, expresa, pero excepcional por cierto, implica el necesario control de parte de la tarea judicial en el funcionamiento de las acciones de garantía constitucional siempre que hayan sido denegadas al pretensor por el Poder Judicial y siempre que al mismo tiempo medie Recurso Extraordinario de Revisión (artículo 41 de la LOTC).

Esto significa que en la facultad excepcional de la jurisdicción negativa de la libertad el Tribunal Constitucional realiza una tarea judicial antes que una función de controlador de la actividad judicial, la de control directo de la Constitucionalidad de las leyes.

En el primer tal caso, sí hay un caso concreto, sí hay partes adversarias y sí hay derechos subjetivos en controversia (no se debe olvidar que las acciones de garantía sólo son procedentes frente a la violación de derechos constitucionales de orden subjetivo, y con legitimación activa real, vigente y existente). Por ello, como aparece obvio, en la jurisdicción negativa de la libertad el Tribunal Constitucional si tiene, bajo las características ya señalas, la facultad de la Judicial Review como derivación judicial (reconducción del Poder Judicial) de la facultad de control sobre las acciones judiciales de garantía, lo que no se debe confundir en ningún momento, ni por cierto ignorar con las verdaderas competencias del Tribunal Constitucional, dentro de una actitud de autocontrol de sus poderes o self restraint que ha caracterizado siempre la actividad y funcionamiento del Tribunal Constitucional en el ejercicio de sus poderes explícitos e implícitos. 
Entonces, no hay actividades constitucionales más opuestas que la Judicial Review y el control concentrado de la constitucionalidad de las leyes, por lo que es necesario determinar siempre con claridad y acierto sus fronteras. Pero al mismo tiempo, hay que establecer bien sus canales de contacto, sobre todo en su sistema como el peruano en donde confluyen ambos al mismo tiempo y en el mismo espacio constitucional (artículos 138으. 2da. parte, y $201^{\circ}$ de la Constitución) en lo que la doctrina constitucional peruana ha venido a denominar «sistema dual» o «sistema mixto» Diríamos, junto con García Belaúnde que estos canales de contacto son, pues, básicamente dos:

i) El control del Tribunal Constitucional sobre la labor del Poder Judicial en la denominada "Jurisdicción Negativa de la Libertad" de la que ya hemos tratado; y,

ii) En la vinculación constitucional que se estatuye por mandato del Art. $39^{\circ}$ de la LOTC respecto del Juez del Poder Judicial frente a un fallo del Tribunal Constitucional, en el que la facultad de la judicial review cede paso por coherencia necesaria y razonable frente a la cualidad mayor y efecto mandatorio en cuanto a la interpretación constitucional de una decisión del tribunal constitucional y por mandato propio de la Constitución Política del Estado.

\section{El Control Difuso en el Poder Judicial y los Procesos Constitucionales}

El Control Difuso como control jurisdiccional de la Constitución, por parte del Poder Judicial, es el organismo constitucional a quien se le ha delegado la potestad de administrar justicia, queda claro que en todo proceso de existir incompatibilidad entre una norma constitucional y una norma legal, los jueces prefieren la primera. Igualmente, prefieren la norma legal sobre todo norma de rango inferior. Como es sabido, los artículos $51^{\circ}$ y $138^{\circ}$, segundo párrafo, de la Constitución, habilitan a cualquier juez, en todo tipo de procesos, a preferir la norma Constitucional sobre cualquier norma inferior que la vulnere y, en consecuencia, a declarar la inaplicación de esta para el caso concreto, de considerarla inconstitucional; esto es lo que se conoce como "control difuso» o incidental de inconstitucionalidad ${ }^{8}$.

Según la Ley Orgánica del Poder Judicial, la sentencia del juez que declara la inaplicación de la norma inconstitucional tendrá que ser revisada por la Corte Suprema, sea por apelación o en consulta, con el fin de asegurar cierta unidad de criterio en el ámbito judicial. No hay duda que lo que prevalece es el respeto a las normas de mayor jerarquía y el Magistrado al momento de administrar justicia no debe ser un mero aplicador de leyes. No obstante, cuando se trata de

8 Eguiguren, Francisco. Los Cambios que el Tribunal Constitucional Necesita. Ubicado en: unuw.justiciaviva.org.pe/informes/ 151a.pdf. Consultado: 14 de junio de 2008. Pág. 3. 
procesos como los de hábeas corpus o amparo, la ausencia de una norma similar en su regulación específica ha llevado a interpretar que si la inaplicación de la norma inconstitucional se da en la sentencia de segunda instancia que declara fundada la acción (convirtiéndose en final), tal decisión de control difuso no se eleva en revisión a la Corte Suprema ni, menos aún, a conocimiento del Tribunal Constitucional. El problema es que se han observado muchos casos en los que coexisten decisiones definitivas y contrapuestas en el nivel de cortes superiores, especialmente en procesos de amparo, respecto de la declaración de inconstitucionalidad e inaplicación al caso concreto de ciertas leyes, situación que atenta contra la seguridad jurídica y la coherencia del sistema.

Encontramos difícil que se apruebe reconducir el control difuso hacia la cuestión de inconstitucionalidad del sistema español, donde el juez ordinario no resuelve sobre la inconstitucionalidad e inaplicación de la norma sino que eleva el asunto al conocimiento y decisión del Tribunal Constitucional, siguiendo luego lo dispuesto por este. Cabría entonces, al menos, establecer que cualquier sentencia judicial con este contenido, incluso en procesos de hábeas corpus, amparo, etcétera, tendrá que ser necesariamente sometida a revisión del Tribunal Constitucional en aras de la mayor certeza y consistencia de la jurisprudencia en materia de la eventual inconstitucionalidad de una norma?

\section{Control Difuso en sede administrativa}

Todo tribunal de la administración pública tiene la facultad y el deber de preferir la Constitución e inaplicar una disposición infraconstitucional que la vulnera manifiestamente, bien por la forma o el fondo, de acuerdo con la Carta Magna. Así lo acordó el Tribunal Constitucional en la sentencia aclaratoria Exp. No 3741-2004-AA/TC, caso Ramón Hernando Salazar Yarlenque, con fecha 13 de octubre de 2006. ${ }^{10}$ dando respuesta a la permanente interrogante de si procedía o no el control difuso en sede administrativa. En este sentido se ha pronunciado el Tribunal Constitucional:

- Que el ejercicio del control difuso administrativo se realiza a pedido de parte; en este supuesto, los tribunales administrativos u órganos colegiados antes aludidos están facultados para evaluar la procedencia de la solicitud, con criterios objetivos y razonables, siempre que se trate de otorgar mayor protección constitucional a los derechos fundamentales de los administrados. En aquellos casos en los que adviertan que dichas solicitudes responden a fines manifies-

Ob. Cit. Eguiguren Francisco. Pág. 4.

10 Diario El Peruano, Jueves 19 de octubre de 2006. sección Derecho. Pág. 17 
tamente obstruccionistas o ilegítimos, pueden establecerse e imponerse sanciones de acuerdo a ley. Excepcionalmente, el control difuso procede de oficio cuando se trate de la aplicación de una disposición que vaya en contra de la interpretación que de ella haya realizado el Tribunal Constitucional, de conformidad con el último párrafo del artículo VI del Título Preliminar del Código Procesal Constitucional; o cuando la aplicación de una disposición contradiga un precedente vinculante del Tribunal Constitucional establecido de acuerdo con el artículo VII del Título Preliminar del Código Procesal Constitucional.

En consecuencia, se deben observar dos presupuestos. Primero, que dicho examen de legalidad sea relevante para resolver la controversia en un proceso administrativo; Segundo, que la ley cuestionada no sea posible de interpretación según la constitución.

La Obligatoriedad del cumplimiento de la Constitución ante una Norma Infraconstitucional

Que el artículo $38 .^{\circ}$ de la Constitución establece que "Todos los peruanos tienen el deber (...) de respetar, cumplir y defender la Constitución y el ordenamiento jurídico de la Nación"; asimismo, el artículo $44 .^{\circ}$ reconoce que "Son deberes primordiales del Estado: (...) garantizar la plena vigencia de los derechos humanos (...); y el artículo $51 .^{\circ}$ prescribe que "La Constitución prevalece sobre toda norma legal; la ley, sobre las normas de inferior jerarquia, y asi sucesivamente (...)"; asimismo, el artículo 1.1. del Título Preliminar de la Ley del Procedimiento Administrativo General establece que "Las autoridades administrativas deben actuar con respeto a la Constitución, la ley y al derecho (...)", y su artículo $10 .^{\circ}$ que "Son vicios del acto administrativo, que causan su nulidad de pleno derecho (...) La contravención a la Constitución, a las leyes o a las normas reglamentarias dentro de las facultades que les estén atribuidas y de acuerdo con los fines para los que les fueron conferidas". Todo lo cual tiene como finalidad tutelar la primacía de la Constitución y la vigencia efectiva de los derechos humanos, de conformidad con el artículo II del Título Preliminar del Código Procesal Constitucional.

De acuerdo a lo manifestado anteriormente, constitucionalmente se ha establecido la obligación de todos los peruanos, del Estado a través de los funcionarios públicos que lo representan, hacer cumplir las leyes, respetando la jerarquía normativa. Y en concordancia a lo estipulado por la constitución tenemos la Ley de Procedimiento Administrativo General que obligan a las autoridades administrativa a actuar con respeto a la constitución. Siguiendo este razonamiento, tendríamos que ante una norma infraconstitucional así se de en la vía administrativa sus autoridades deben preferir la norma constitucional de igual forma como se hace a nivel judicial siguiendo las pautas del Tribunal Constitucional. 


\section{Conclusiones y recomendaciones}

1. Como hemos podido apreciar de la Sentencia del Tribunal Constitucional, Expediente 007-2001-AI/TC, publicada el 1 de febrero de 2003, se ha pronunciado al respecto, en este sentido el control difuso, está reservado para ser aplicado por aquellos órganos constitucionales como el Poder Judicial, el Jurado Nacional de Elecciones o el propio Tribunal Constitucional que ejercen funciones jurisdiccionales en las materias que les corresponden y no para los órganos de naturaleza o competencias eminentemente administrativas", como es el caso del Tribunal Fiscal. Con esto, se amplia los órganos jurisdiccionales que pueden aplicar el control difuso, comprendido en el artículo $138^{\circ}$ segundo Párrafo de la Constitución, que por estar dentro del Capitulo de Poder Judicial, pareciera que solo estaría reservado para este órgano. Sin embargo, el Tribunal Constitución se ha pronunciado y ha ampliado a otros órganos constitucionales que son jurisdiccionales, empero ha sido cauto y no ha querido comprender a otros órganos como son los de sede administrativa, es por ello que concordando con el voto discordante del magistrado constitucional doctor Aguirre Roca, quien en el Exp. N. ${ }^{\circ}$ 0499-2002-AA/TC, dejo constancia, no compartir el criterio de sus fundamentos 1 . y 2 ., de la referida sentencia creyendo, que el Tribunal Fiscal tiene competencia para preferir la regla constitucional a la de menor jerarquía; $\mathrm{y}$, de otro, que las exoneraciones tributarias tienen rango constitucional, pensamos que debiera ser usado por otros órganos sean administrativos o jurisdiccionales.

2. Que, si bien el control difuso se creó para órganos constitucionales que ejercen funciones jurisdiccionales, y por ello la encontramos en el Capitulo del Poder Judicial, dentro de la Constitución del Perú de 1993, también es cierto que en temas constitucionales hay una evolución constante y hoy en día existen otros organismos que administran justicia que aún cuando son administrativos sus fallos que son causa decidida tienen efectos en la vida nacional, es por ello que creemos que deberá reformarse la constitución en cuanto al artículo 138 y comprender a todos aquellos órganos que administren justicia, para que tengan la posibilidad de apartarse de normas evidentemente contrarias a la constitución, sin tener que esperar que sea declarada inconstitucional, cosa que puede llevar mucho tiempo en el mejor de los casos, y en el peor de los casos no solicitarse su inconstitucionalidad nunca, $y$ tener que aplicar normas evidentemente contrarias a la constitución, causando con ello un perjuicio irreparable a sus administrados. Sin embargo, al igual que en el poder judicial, esta resolución antes de causar estado, deberá subir en consulta al tribunal constitucional a efectos de verificar la inconstitucionalidad o no, de una norma.

3. Si todos los peruanos le debemos obediencia y respeto a la constitución, desde el lado donde nos encontremos debemos procurar que ese respeto no se vea violentado, y para ello debemos buscar los mecanismos de control. Por otro lado, sabemos que el poder judicial tiene 
la facultad de inaplicar una norma inconstitucional a través del control difuso; sin embargo, nuestro sistema marcadamente codiguero, ha acondicionado a los jueces a ser meros aplicadores de las normas, y esperan a que el Tribunal Constitucional la declare inconstitucional para a partir de ese momento amparar el derecho de los afectados, prefiriendo aplicar la ley en vigencia, para evitarse procesos por prevaricato. Sin embargo, el Tribunal Constitucional, organismo llamado a controlar la constitucionalidad de las leyes a través del proceso de inconstitucionalidad, cuando administra justicia, sobre todo en los procesos de amparo y habeas corpus, utilizando el sistema de control difuso, puede apartarse de aquella norma inconstitucional para ese caso en particular. 


\section{Bibliografía}

- Blume Fortini, Ernesto. «El Tribunal Constitucional Como Supremo Interprete de la Constitución». Derecho PUC, núm. 50. Diciembre de 1996.

- Diario El Peruano, sección Derecho. Jueves 19 de octubre de 2006.

- Eguiguren, Francisco. «Los Cambios que el Tribunal Constitucional Necesita». Disponible en la Web: www.justiciaviva.org.pe/informes/151a.pdf. CONSULTADO: 15 de septiembre de 2007.

- García Pelayo, Manuel. 1961. «Derecho Constitucional Comparado». Madrid. 6ta. Edición. Castilla.

- Landa, César. «Tribunal Constitucional y Estado de Derecho». Lima, PUCP, 1999.

- Ortecho Villena, Víctor Julio, «Control Difuso e Interpretación Constitucional. Disponible en http://hechosdelajusticia.org/quinta/38.rtf. CONSULTADO: 17 de Septiembre de 2007.

- Qquiroga León, Aníbal, «El Control Difuso», Diario El Comercio Viernes, 24 de enero de 1997.

- Red de Información Jurídica JURISPRUDENCIA CONSTITUCIONAL, Jurisprudencia sobre el control difuso de la constitucionalidad de las normas jurídicas Perú. Disponible en: http://www.cajpe.org.pe/RIJ/bases/juris-nac/difuso.htm. CONSULTADO: 23 de septiembre de 2007.

- Rios A., Lautaro. El Control Difuso de Constitucionalidad de la Ley en la República de Chile. . Ius et Praxis. [online]. 2002, vol.8, no.1 [citado el 15 octubre 2006], p.389-418.

- Disponible en la World Wide Web:http://www.scielo.cl/ scielo.php?script =sci_arttext \& pid=S0718-00122002000100021 \&lng=es\&nrm=iso $>$.ISSN0718-0012. CONSULTADO: 17 de septiembre de 2007.

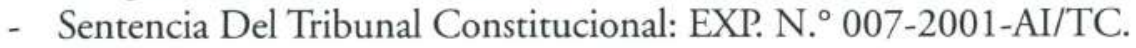

- Sentencia Del Tribunal Constitucional: EXP. N. ${ }^{\circ} 0499-2002-A A / T C$

- Sentencia Del Tribunal Constitucional: EXP. N. ${ }^{\circ}$ 3741-2004-AA/TC 